\title{
Specific Routing of Retinal Ganglion Cell Axons at the Mammalian Optic Chiasm During Embryonic Development
}

\author{
David W. Sretavan \\ Laboratory of Neurobiology, Rockefeller University, New York, New York 10021
}

During development of the mammalian CNS, axons encounter multiple pathway choices on their way to central target structures. A major pathway branch point in the visual system occurs at the optic chiasm, where retinal ganglion cell axons may either enter the ipsilateral or the contralateral optic tract. To investigate whether embryonic mouse retinal ganglion cell axons, upon reaching the optic chiasm, selectively grow into the correct pathway, developing retinal ganglion cells were retrogradely labeled using either $1,1^{\prime}$-dioctadecyl-3,3,3',3'-tetramethylindocarbocyanine perchlorate (Dil) or fluorescent microspheres placed into the optic tract on one side. The distribution of ipsilaterally and contralaterally projecting ganglion cells in the embryo was then examined and compared to that of the adult animal. Results show that axon routing at the chiasm is already extremely adult-like as early as embryonic day 15 (E15), shortly after retinal axons arrive at the chiasm. [Retinal ganglion cell neurogenesis = E11-E18 (Drager, 1985); birth = E21.] Throughout the development of this pathway, routing errors are infrequent and are on the order of only about 3-8/1000 retinal ganglion cells. Thus, embryonic retinal ganglion cell axons do not project randomly at the optic chiasm but instead appear to be highly specific in their choice of pathway.

To learn how correct pathway choices are made, retinal axons were retrogradely labeled with Dil and their trajectories at the optic chiasm were reconstructed. Results show that ipsilaterally and contralaterally projecting axons are highly intermixed as they enter the chiasm region but selectively grow into the correct pathway. For example, a contralaterally projecting axon near the entrance of the ipsilateral optic tract will turn and bypass this pathway and grow towards the midline to head into the contralateral optic tract. Similarly, axons far away from the ipsilateral optic tract frequently turn abruptly at right angles to enter the ipsilateral tract, directly crossing over contralaterally projecting axons heading to the opposite side. The sorting out of intermixed ipsilaterally and contralaterally projecting retinal axons into the appropriate optic tracts strongly suggests the presence

\footnotetext{
Received Dec. 4, 1989; revised Jan. 26, 1990; accepted Jan. 31, 1990.

I wish to thank Dr. Torsten Wiesel for encouragement and support throughout this study and Drs. Edward Callaway, Lawrence Katz, Carla Shatz, and Torsten Wiesel for insightful comments on the manuscript. This study was funded through a Jacob Javits Center of Excellence in Neuroscience Grant awarded to Rockefeller University and a Squibb postdoctoral fellowship in the basic neurosciences awarded to the author.

Correspondence should be addressed to David W. Sretavan, M.D., Ph.D., Laboratory of Neurobiology, Rockefeller University, 1230 York Avenue, New York, NY 10021

Copyright (c) 1990 Society for Neuroscience $0270-6474 / 90 / 061995-13 \$ 02.00 / 0$
}

of specific guidance cues at the optic chiasm during embryonic development. Together, results from this study demonstrate that the pattern of axon projection at the adult mammalian optic chiasm is gradually built upon a highly specific pattern of axon routing laid down early during development.

The manner in which the highly specific axon pathways characteristic of the adult CNS are formed during development is not fully understood. Studies in insects have shown that developing axons grow along precise routes to form mature patterns of axon pathways very early in development (Ho and Goodman, 1982; Bentley and Caudy, 1983; Goodman et al., 1984; Klose and Bentley, 1989, for review). In the vertebrate PNS, axons of embryonic motoneurons in both the chick (LanceJones and Landmesser, 1981; Landmesser, 1984; Tosney and Landmesser, 1985a, b) and the zebrafish (Eisen et al., 1986, 1989; Westerfield and Eisen, 1988) also exhibit a remarkable degree of specificity in their choice of pathway en route to precise muscle groups. While it has been possible in these systems to examine the process of axon routing in great detail starting at early stages of axon outgrowth, currently little is known about the initial stages of axon pathway formation within the embryonic mammalian CNS.

In the present study, the specificity of axon routing at a defined pathway branch point in the mammalian visual system was examined starting at early stages of development. At the adult optic chiasm, retinal ganglion cells in specific parts of the retina send axons into either the ipsilateral or contralateral optic tract. In the rodent visual system, ipsilaterally projecting ganglion cells are localized to ventral-temporal retina, while contralaterally projecting ganglion cells are found throughout the retina (Drager and Olsen, 1980; Lund et al., 1980). This precise pattern of chiasmatic routing is essential to the proper function of the visual system by ensuring that information received in the 2 eyes regarding an object in space is sent to the same side of the brain for processing (for review, see Guillery, 1983).

During embryonic life, the retina is formed as an outpouching of the CNS and remains attached to the diencephalon by the optic stalk. Axons of retinal ganglion cells upon leaving the retina, grow along the optic stalk to reach the region of the optic chiasm located at the ventral midline of the diencephalon. Once at the optic chiasm, retinal axons are faced with a pathway choice and may choose to enter either the ipsilateral optic tract on the same side of the brain or else cross contralaterally to the optic tract on the opposite side. In the mouse, retinal ganglion cells are born over an extended period of time from embryonic day (E) 11 to E18 (Drager, 1985). Retinal axons grow along the 
optic nerve and first arrive at the optic chiasm around E12.5 and enter the optic tracts at about E13 (Silver, 1984). The axons of the last retinal ganglion cells to be born likely grow into the chiasm sometime around birth (E21). In this study, the specificity of embryonic retinal axon routing at the optic chiasm was examined starting at E15, soon after significant numbers of retinal axons have entered the optic tracts. The results show that embryonic retinal ganglion cell axons are highly specific in their choice of pathway at the optic chiasm. A brief description of this work has been presented (Sretavan, 1989).

\section{Materials and Methods}

Animals. Experiments were carried out using $\mathrm{C} 3 \mathrm{H}$ mice, a nonalbino strain of mouse. Timed pregnant mice were bred in an in-house breeding colony with the day of vaginal plug detection counted as E0. Gestation is $21 \mathrm{~d}$. Day of birth was counted as P0.

Surgical procedures. Pregnant mice were anesthetized by an intraperitoneal injection of $2.5 \mathrm{mg}$ sodium pentobarbital. Cesarian sections were carried out under aseptic conditions. Following delivery of embryos, adult mice were killed using an overdose of sodium pentobarbital. All embryos and postnatal mice were anesthetized using hypothermia.

DiI labeling in fixed tissue. In the first set of experiments, the carbocyanine dye, 1, 1'-dioctadecyl-3,3,3',3'-tetramethylindocarbocyanine perchlorate (DiI, Molecular Probes, OR) was used to retrogradely label embryonic retinal ganglion cells and to determine the distribution of ipsilaterally and contralaterally projecting ganglion cells in the embryo compared to the adult. DiI has previously been shown to be an excellent retrograde neuronal tracer (Honig and Hume, 1986) and labels long axonal processes and cell bodies even in fixed tissues (Godement et al., 1987a).

After delivery via cesarian section, embryos were immersion fixed in $4 \%$ paraformaldehyde (in $0.1 \mathrm{M}$ phosphate buffer, $\mathrm{pH} 7.4$ ) at $4^{\circ} \mathrm{C}$ for $24-48 \mathrm{hr}$ with continuous stirring. The top of the cranium was removed to promote entry of fixative. Embryos at E1 8 or older and postnatal animals were first perfused intracardially with $4 \%$ paraformaldehyde and then immersion fixed. For retrograde labeling of embryonic retinal ganglion cells, the cortex was removed and crystals of DiI picked up on tips of glass micropipettes were placed into the optic tract approximately halfway between the developing lateral geniculate nucleus and the optic chiasm. Care was taken not to label too close to the optic chiasm in order to avoid accidental labeling of retinal axons projecting to the opposite side. Labeled specimens from E13-15 embryos were stored at $37^{\circ} \mathrm{C}$ for 1 week, while those from embryos at E 16 or older and postnatal animals were stored for 2 weeks. The distribution of retrogradely labeled retinal ganglion cells was examined in $50-\mu \mathrm{m}$-thick horizontal vibratome sections of the retina. The plane of section was tilted up anteriorly approximately $30^{\circ}$ from the horizontal in order to cut perpendicularly through the ventral-temporal part of the retina. DiI fluorescence was viewed using a standard rhodamine filter set.

For anterograde labeling of axons originating from specific parts of the embryonic retina, the cornea and lens from embryos fixed with $4 \%$ paraformaldehyde were removed to expose the retina. Small crystals of DiI picked up on tips of glass micropipettes were manually placed in selected retinal regions under visual guidance using a dissecting microscope. Labeled tissue was stored as described above. To examine the anterograde axon projection pattern following the labeling of selected retinal areas, the region of the optic chiasm was sectioned horizontally at $50 \mu \mathrm{m}$ to ensure that even small axon projections were identified.

Microsphere labeling in living in vitro embryonic preparations. In addition to retrograde labeling using DiI, embryonic retinal ganglion cells were also retrogradely labeled in a separate set of experiments using fluorescent microspheres placed into the optic tract. After delivery via cesarian section, embryos were dissected in oxygenated Ringer's solution at $4^{\circ} \mathrm{C}$ and the retinas and optic nerves isolated together with a portion of the diencephalon containing the optic chiasm and optic tracts. Four to 8 pressure injections of fluorescently labeled microspheres (Katz et al., 1984) were made into one optic tract. After rinsing 3 times with fresh Ringer's solution, the cornea, sclera, and pigment epithelial layer were removed to promote tissue oxygenation during incubation. In E16 and older embryos, the lens was also removed to allow direct perfusion of the retinal ganglion cell layer. In vitro preparations were then continuously superfused with tissue culture medium at $25 \mathrm{ml} / \mathrm{hr}$ and in- cubated at $34^{\circ} \mathrm{C}$ in a $95 \%$ oxygen $5 \% \mathrm{CO}_{2}$ atmosphere. [Each $100 \mathrm{ml}$ of medium contained $83 \mathrm{ml} \mathrm{L}-15$ culture medium (Gibco), $17 \mathrm{ml}$ of $150 \mathrm{~mm} \mathrm{NaHCO}, 16 \mathrm{~mm}$ dextrose, and $1 \mathrm{mg}$ gentamicin.] After 10 $12 \mathrm{hr}$, preparations were fixed overnight in $4 \%$ paraformaldehyde at $4^{\circ} \mathrm{C}$ and then sectioned horizontally at $50 \mu \mathrm{m}$ on a vibratome. This allows the orientation of the eyes within the cranium to be correctly maintained and is superior to whole-mounts, which require the mechanical fiattening of fragile embryonic retinas. Rhodamine labeled microspheres were visualized using a standard filter set.

In order to reconstruct the overall global distribution of ipsilaterally and contralaterally projecting retinal ganglion cells, the position of each microsphere-labeled retinal ganglion cell was plotted onto camera lucida drawings of individual retinal sections. The total linear length of the retinal ganglion cell layer in each retinal section was then represented as a straight line, and the position of labeled retinal ganglion cells within the retinal section transposed onto this line. All the retinal sections from a given eye were then restacked up on top of each other to reconstruct the overall distribution of labeled retinal ganglion cells within the whole retina.

Photoconversion of DiI-labeled retinal axons. To facilitate the reconstruction of individual ipsilaterally and contralaterally projecting retinal axons at the optic chiasm, tissue sections containing DiI-labeled axons and their growth cones were photoconverted to substitute the DiI fluorochrome with a stable diaminobenzidine (DAB) reaction product which can be observed using bright-field optics. Vibratome tissue sections containing DiI-labeled material were placed onto a subbed glass microscope slide in a drop of $0.1 \mathrm{M}$ Tris buffer $\left(\mathrm{pH} 8.2,4^{\circ} \mathrm{C}\right)$ containing $1.5 \mathrm{mg} / \mathrm{ml} \mathrm{DAB}$. The section was then exposed to a fluorescent light source equipped with a rhodamine filter set. During photoconversion, the Tris/DAB solution was aspirated off every $10-15 \mathrm{~min}$ and replaced with fresh Tris/DAB solution kept at $4^{\circ} \mathrm{C}$. Photoconversion was terminated when the desired density of DAB axon labeling was achieved (approximately $45-60 \mathrm{~min}$ ). The procedure used is similar to that described for the photoconversion of other fluorochromes (Maranto, 1982; Sandell and Masland, 1988).

\section{Results}

\section{Distributions of ipsilaterally and contralaterally projecting} retinal ganglion cells during embryonic development

The mature pattern of retinal ganglion cell axon routing at the optic chiasm could arise via 1 of 2 alternative mechanisms. First, embryonic retinal ganglion cells in different parts of the retina could be specified in their choice of pathway, and upon arrival at the optic chiasm, retinal axons may be capable of selectively growing into the appropriate optic tract. If so, the distribution of ipsilaterally and contralatcrally projecting retinal ganglion cells in the embryonic retina should closely resemble that seen in the adult. In this case, ipsilaterally projecting retinal ganglion cells should be found only in the ventral-temporal part of the retina, while contralaterally projecting ganglion cells should be present throughout the retina. An alternative is that embryonic retinal ganglion cell axons may initially project somewhat randomly at the chiasm and the mature pattern of chiasmatic routing is formed only later after the elimination of axon-routing errors. In this situation, the distribution of ipsilaterally and contralaterally projecting ganglion cells in the embryonic retina will be quite unlike that found in the adult. To distinguish between these 2 possibilities, DiI was placed into one optic tract of fixed mouse embryos to retrogradely label retinal ganglion cells and to reveal the distribution of ipsilaterally and contralaterally projecting ganglion cells at different developmental ages. Following the placement of DiI into the optic tract on one side, ipsilaterally projecting retinal ganglion cells are retrogradely labeled in the eye on the same side, while contralaterally projecting ganglion cells are labeled in the opposite eye.

Results from these experiments show that as early as E15, that is, $2 \mathrm{~d}$ after the retinal axons grow into the optic tracts and well before the majority of retinal axons have reached the chiasm, 

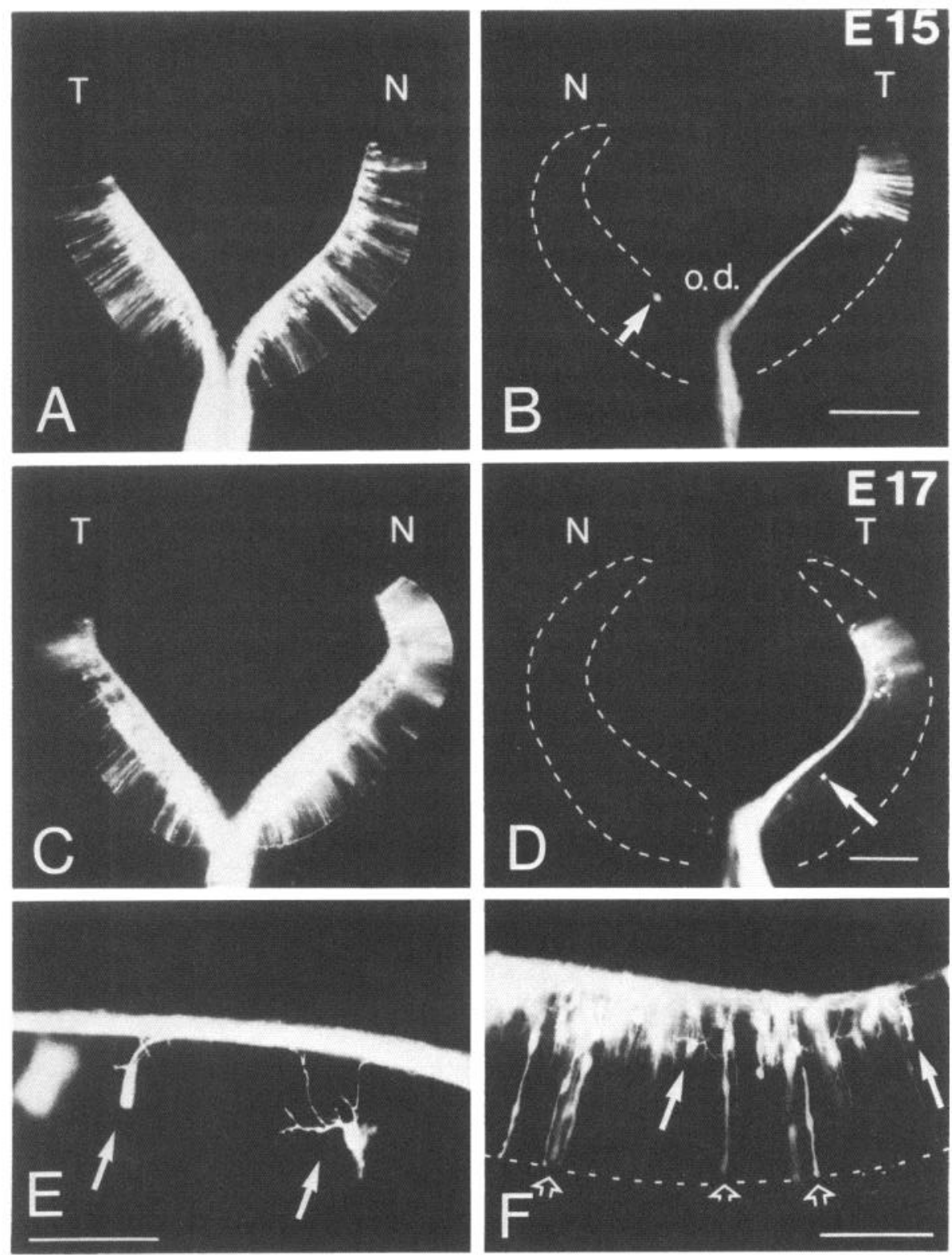

Figure 1. Distribution of ipsilaterally and contralaterally projecting retinal ganglion cells during embryonic development. $A$ and $B$, Horizontal sections through the retinas of an E15 embryo showing the location of contralaterally $(A)$ and ipsilaterally $(B)$ projecting ganglion cells. Note that as in the adult, ipsilaterally projecting retinal ganglion cells at E15 are restricted to the temporal part of the retina, while contralaterally projecting ganglion cells are distributed throughout. $N$, nasal retina; $T$, temporal retina; o.d., optic disc. Scale bar, $100 \mu \mathrm{m}$. $C$ and $D$, Horizontal sections through the retinas of an E17 embryo. A pattern similar to that at E15 is seen. Scale bar, $100 \mu \mathrm{m}$. Arrows in $B$ and $D$ point to rare ipsilaterally projecting ganglion cells outside ventraltemporal retina. E, Examples of retrogradely DiI-labeled retinal ganglion cells (solid arrows) in an E15 embryo. Vitreal surface is towards the top. Scale bar, 25 $\mu \mathrm{m}$. The cell on the right has 2 processes which appear to travel in opposite directions within the optic fiber layer. $F$ Retinal section showing elongated radially aligned retinal cells (open arrows) found in close proximity to retinal ganglion cells with dendritic processes ( $\mathrm{sol}$ id arrows). Such elongated cells may represent Müller glia, retinal neuroblasts, or immature retinal ganglion cells. Scale bar, $50 \mu \mathrm{m}$. the distribution of ipsilaterally and contralaterally projecting ganglion cells in the retina was almost exactly that seen in the adult animal. Figure $1, A, B$, shows the distribution of ipsilaterally and contralaterally projecting retinal ganglion cells in an E15 embryo. The figure shows horizontal sections through the optic disc region of both the contralateral and ipsilateral retinas. Contralaterally projecting retinal ganglion cells (Fig. $1 \mathrm{~A}$ ) were found in all regions extending from nasal to temporal retina. In contrast, retinal ganglion cells projecting ipsilaterally (Fig. 1B) were located only within a region of temporal retina. The pattern seen 2 d later at E17 was very similar and is shown in Figure $1, C, D$. Although at this stage the retinas have grown larger, contralaterally projecting ganglion cells were again found throughout the retina and ipsilaterally projecting ganglion cells were confined to temporal retina. While a rare ectopically located ipsilaterally projecting ganglion cell may sometimes be found (Fig. 1, B, D, arrows), retinal ganglion cells projecting ipsilaterally at these embryonic ages were restricted almost exclusively to ventral-temporal retina.
Although retrograde labeling using DiI revealed the distributions of ipsilaterally and contralaterally projecting retinal ganglion cells, this technique also labeled other cell types in the embryonic retina. Higher-magnification views of retinal ganglion cells labeled with DiI are shown in Figure $1, E, F$. Two retinal ganglion cells at different stages of maturation can be seen in figure $1 E$. Figure $1 F$ shows the typical DiI-labeling pattern seen at E15 and E17, where labeled retinal ganglion cells coexist with elongated cells radially spanning the thickness of the retina. These elongated cells resemble Müller glial cells, although some may be neuroblasts or immature retinal ganglion cells which maintain attachments with both the vitreal and scleral surfaces (Morest, 1970). Since such labeled elongated cells were always found in close proximity to clearly defined retinal ganglion cells, they could be labeled by passage of DiI from ganglion cells at regions of close membrane contact between these 2 cell populations. A similar type of "transcellular" labeling has been seen between embryonic retinal axons and neuroepithelial cells at the optic chiasm (Godement et al., 1987a). 

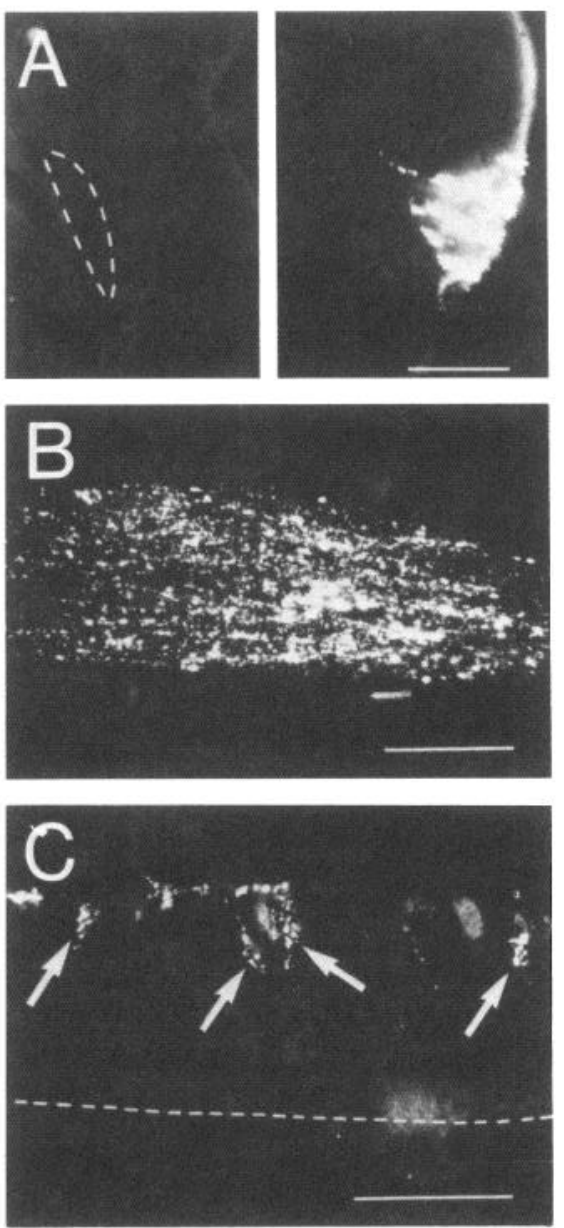
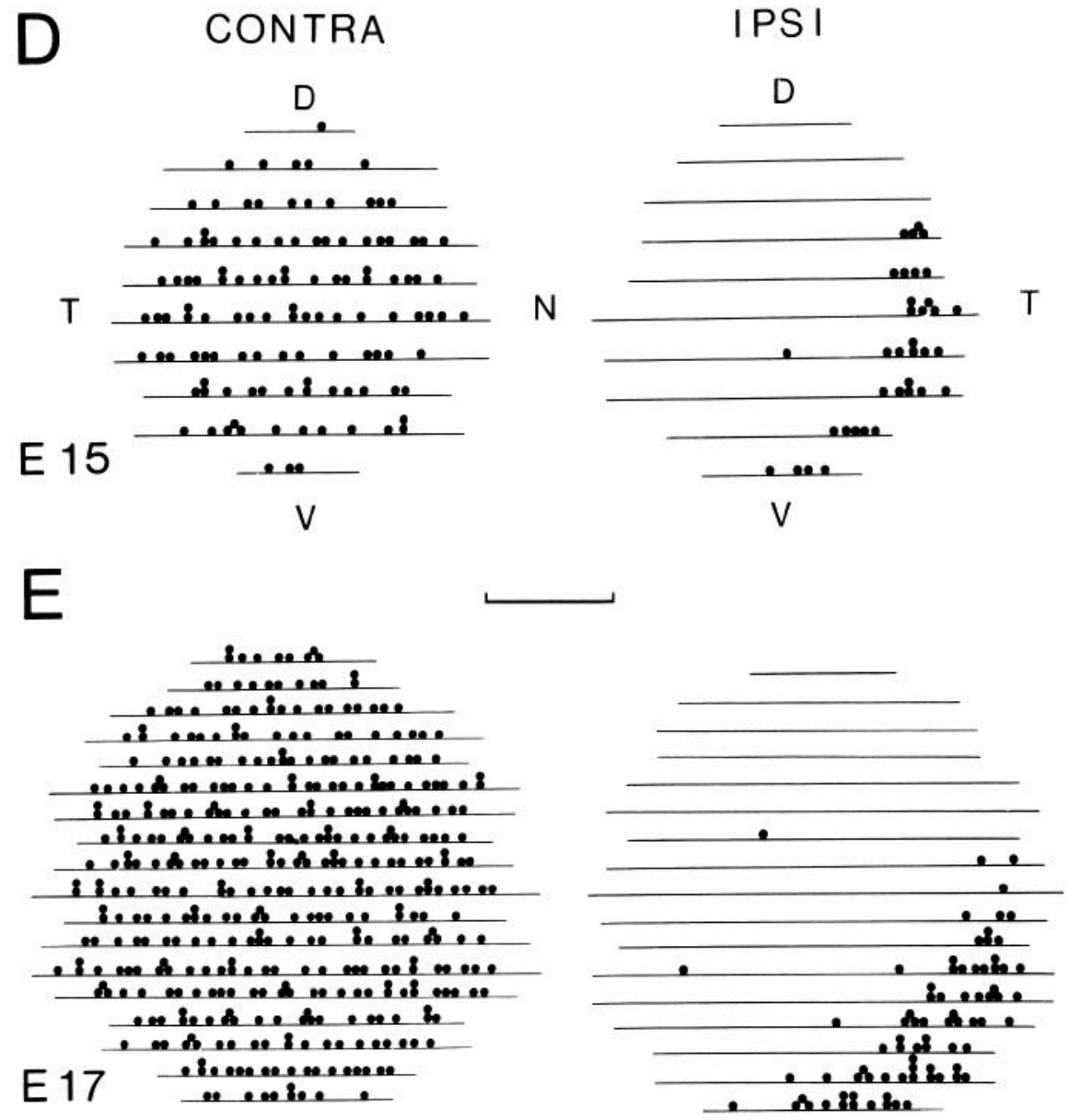

Figure 2. Retrograde labeling of embryonic retinal ganglion cells using fluorescent microspheres. A, Horizontal section through the diencephalon of an in vitro preparation from an E15 embryo showing microsphere injections into one optic tract. The opposite optic tract (dotted line) was completely unlabeled. Scale bar, $200 \mu \mathrm{m}$. B. Longitudinal section through the contralateral optic nerve showing numerous retrogradely transported fluorescent microspheres. Scale bar, $100 \mu \mathrm{m}$. C, Examples of microsphere-labeled retinal ganglion cells (arrows) from an E15 embryo. Scale bar, $50 \mu \mathrm{m}$. The distance from the labeled retinal ganglion cells to the dotted line on the bottom represents the thickness of the retina. $D$ and $E$, Reconstructions of the retinas from an E15 and an E17 embryo showing the distribution of contralaterally (left) and ipsilaterally (right) projecting retinal ganglion cells. Horizontal black lines represent the linear extent of the retinal ganglion cell layer in each retinal section. Individual labeled ganglion cells are shown as black dots. As in the adult, ipsilaterally projecting ganglion cells at E15 and E17 were restricted to ventral-temporal retina, while contralaterally projecting ganglion cells were found in all retinal regions. The small number of labeled ganglion cells at E15 is consistent with the fact that even though the majority of ipsilaterally projecting ganglion cells have been born by E15 (Drager 1985), only some will have extended axons into the optic tract. Scale bar, $200 \mu \mathrm{m}$.

\section{Retrograde labeling of retinal ganglion cells using fluorescent microspheres}

In order to avoid the possibility that the true distribution of ipsilaterally and contralaterally projecting ganglion cells may have been distorted by the presence of these labeled elongated cells, retinal ganglion cells were exclusively retrogradely labeled in a second set of experiments using rhodamine-labeled latex microspheres (Katz et al., 1984) injected into the optic tract. Since optic tract labeling in mouse embryos in vivo is technically difficult and embryo survival is limited, these experiments were performed using a novel preparation consisting of the retinas, optic nerves, chiasm, and optic tracts maintained in vitro (see Materials and Methods.).

Microspheres injected into in vitro preparations remained localized to the optic tract on one side (Fig. $2 A$ ). The opposite optic tract regions were always completely unlabeled. Retrogradely transported microspheres were visible in the optic nerves
(Fig. $2 B$ ) and retinal ganglion cells (Fig. 2C). Labeled cells were localized to the retinal ganglion cell layer, indicating that retrogradely transported microspheres remained within ganglion cells and were not passed into other cell types.

The distributions of ipsilaterally and contralaterally projecting retinal ganglion cells at E15 and E17 obtained using microspheres were very similar to those obtained using DiI (Fig. $2, D, E)$. To obtain the overall global distribution of ipsilaterally and contralaterally projecting ganglion cells labeled with microspheres, the position of each microsphere-labeled retinal ganglion cell was first marked onto camera lucida drawings of retinal sections. Retinal sections from a given eye were then restacked in order to reconstruct the whole retina. In the reconstructions shown in Figure 2, $D, E$, the horizontal black line represents the total linear length of the retinal ganglion cell layer of each retinal section, and each black dot represents one microspherelabeled retinal ganglion cell.

Similar to the results obtained using DiI, ipsilaterally pro- 

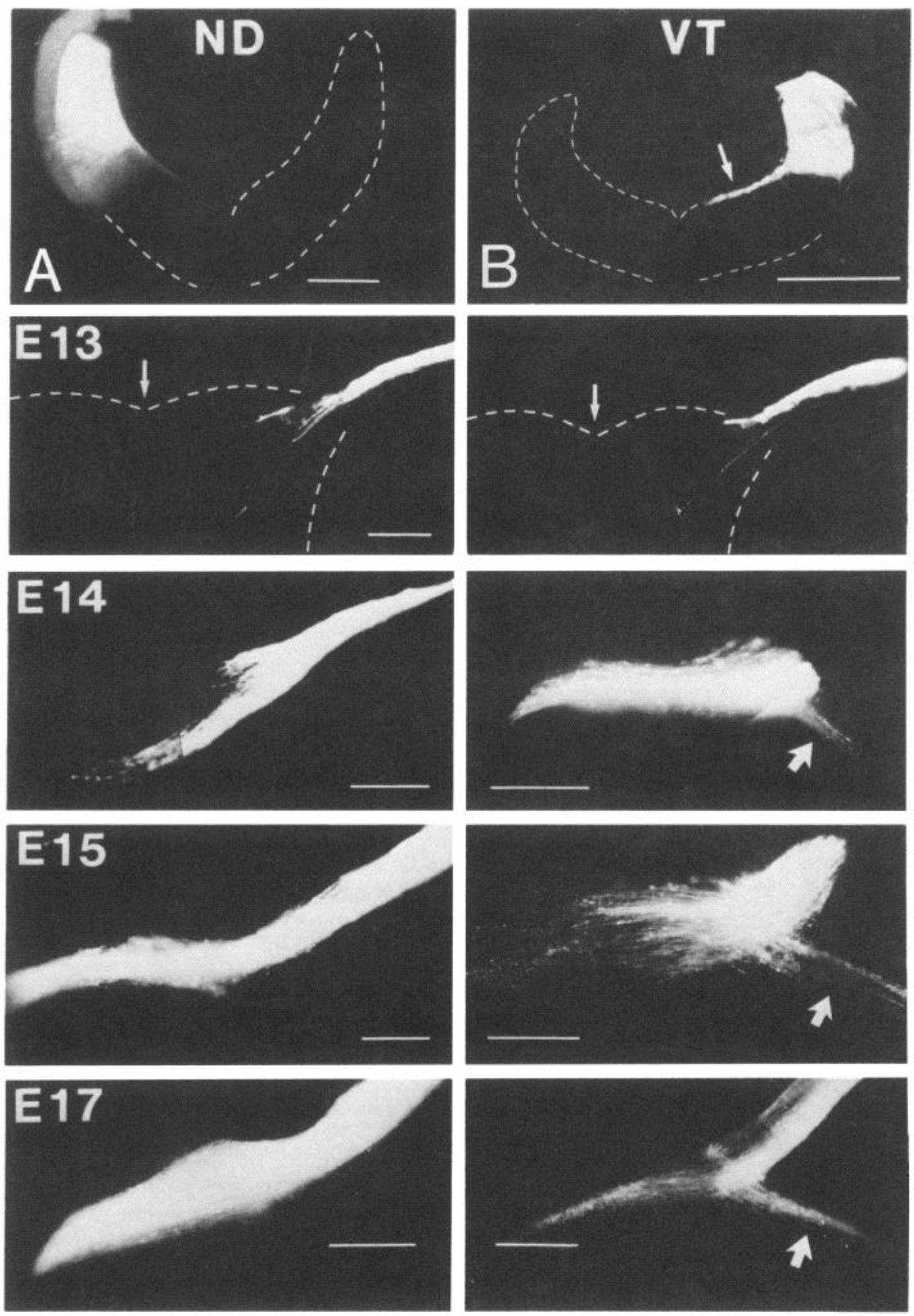

Figure 3. Axon projection patterns originating from embryonic nasal-dorsal and ventral-temporal retina. $A$, Section through the labeling site in nasaldorsal retina of an E16 embryo photographed using fluorescence optics. Local placement of DiI crystals labeled a discrete portion of the retina. Scale bar, $100 \mu \mathrm{m} . B$, Labeling site in ventraltemporal retina of an E13 embryo. The arrow points to axons originating from the labeled region growing towards the optic disc. Scale bar, $100 \mu \mathrm{m}$. Bottom, Chiasmatic projection patterns originating from nasal-dorsal (left column) and ventral-temporal retina (right col$u m n$ ) in embryos at E13-17. Horizontal views of the chiasm are presented with optic nerves at the top and optic tracts at the bottom. Photographs obtained at different focal planes were assembled as a montage. The chiasm region at E13 is outlined with an arrow pointing to the midline. Similar to the projection patterns found in the adult animal, embryonic nasal-dorsal axons grow contralaterally, while ventraltemporal retina form both an ipsilateral (arrows) and a contralateral projection. Scale bars: E13, $50 \mu \mathrm{m}$; E14 and 15, $100 \mu \mathrm{m} ; \mathrm{E} 17,200 \mu \mathrm{m}$. jecting cells at both E15 and E17 were once again restricted to ventral-temporal retina. Contralaterally projecting ganglion cells were present throughout all regions of the retina. Thus, results from retrograde labeling experiments using either DiI or fluorescent microspheres show that ipsilaterally and contralaterally projecting retinal ganglion cells are not randomly mixed throughout the embryonic retina, but are instead distributed in a precise adult-like pattern. Since both ipsilaterally and contralaterally projecting ganglion cells are born starting at E11 (Drager, 1985), it is not surprising that both types of ganglion cells could be retrogradely labeled from the optic tract at E15. However, it is remarkable that at these ages, contralaterally projecting ganglion cells are generated throughout the entire retina, whereas ipsilaterally projecting ganglion cells are born within a circumscribed region.

\section{Axon projection patterns from different retinal regions}

The early presence of an adult-like distribution of ipsilaterally and contralaterally projecting ganglion cells suggests that embryonic axons from different parts of the retina are capable of selectively growing into the appropriate optic tract. If so, the chiasmatic routing of projections originating from embryonic ventral-temporal retina should be quite different from that of nasal-dorsal retina. To verify this, small DiI crystals were placed within the retina of fixed embryos for anterograde labeling of axons originating from these 2 regions. In all cases, the DiI- 
Figure 4. Ipsilaterally projecting retinal ganglion cclls located outside ventral-temporal retina at different developmental ages. At each age, the retina ipsilateral to the labeled optic tract is reconstructed as described in Figure 2. Each retina is then divided into thirds of equal area, with the ventral-temporal third shaded. The large numbers of ipsilaterally projecting ganglion cells normally present within ventral-temporal retina are not shown. Individual microsphere-labeled retinal ganglion cells outside this region are represented as solid dots. Note that increasing numbcrs of such cclls arc found in late cmbryonic life and reach a peak around birth. Scale bar, $1 \mathrm{~mm}$.

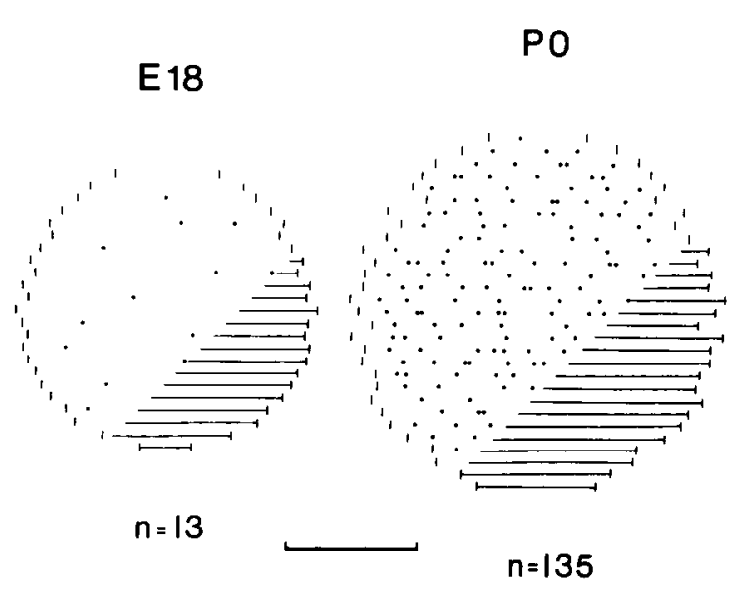

P3

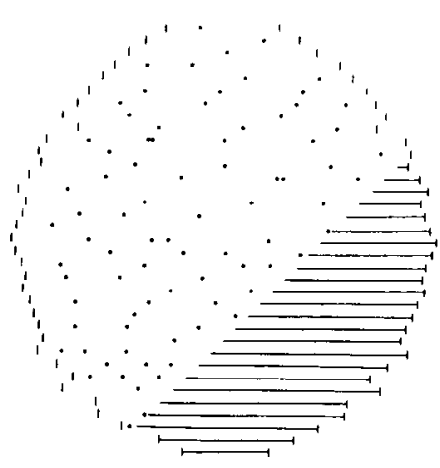

$n=81$ labeled region was highly restricted and did not spread throughout the retina. Examples of DiI-labeling sites within the retina of $\mathrm{E} 13$ and $\mathrm{E} 16$ embryos are shown in Figure 3, $A, B$, respectively. The lower part of Figure 3 shows axon projections at E13-17 arising from nasal-dorsal and ventral-temporal retina.

Axons from both ventral-temporal and nasal-dorsal retina reach the chiasm at about $E 13$, half a day after the first axons from central retina (Silver, 1984; D. Sretavan, unpublished observations). One day later at E14, a difference in the projections from the 2 retinal regions can already be identified. At this age, nasal-dorsal axons grow contralaterally without entering the ipsilateral optic tract. In contrast, although many axons from ventral-temporal retina do project contralaterally as expected, a small but distinct ipsilateral projection is clearly present (Fig. 3: E14, arrow). By E15, this ipsilateral projection is larger and more clearly defined. The projection patterns at E17 closely resemble those originating from corresponding regions in the adult. Nasal-dorsal retina forms a contralateral projection, while ventral-temporal retinal axons project into either the contralateral or ipsilateral optic tract.

\section{Axon routing errors}

A striking feature of embryonic retinal projections is that retinal ganglion cells outside ventral-temporal retina project almost exclusively into the contralateral optic tract. Although ganglion cells in this region at E 15 and $E 17$ rarely project inappropriately into the ipsilateral side, as additional retinal ganglion cells are born and more axons arrive at the chiasm, such projection errors were more numerous at later developmental ages. When the distribution of microsphere-labeled, ipsilaterally projecting retinal ganglion cells outside ventral-temporal retina between E1 8 and P3 were examined (Fig. 4), increasing numbers of ipsilaterally projecting cells were found outside ventral-temporal retina starting at E18 (day of birth is E21, or P0). Their numbers reached a peak around birth and then decreased postnatally. Previous studies have shown that ipsilaterally projecting retinal ganglion cells outside of ventral-temporal retina are selectively eliminated during rodent postnatal development (Jeffrey and Perry, 1982; Martin et al., 1983; Insausti et al., 1984) and that very few of these cells remain in the adult (Drager and Olsen, 1980; Lund et al., 1980). Thus, while embryonic retinal axons are highly specific in their choice of pathway at the chiasm, a small amount of projection error appears to be involved in this process of axon pathfinding. As more retinal ganglion cells are generated at later stages of development and their axons enter the chiasm, the absolute number of inappropriately projecting ganglion cells increases and more projection errors become apparent.

In order to obtain a rough estimate of the amount of projection error associated with the formation of this pathway, the ratio of ipsilaterally (inappropriately) to contralaterally (appropriately) projecting retinal ganglion cells outside ventral-temporal retina was calculated at different embryonic ages. To do so, retinal ganglion cells were retrogradely labeled from the optic tract and the total number of ipsilaterally projecting ganglion cells outside ventral-temporal retina was counted in the ipsilateral eye. In the same animal, contralaterally projecting ganglion cells outside ventral-temporal retina were counted in the eye opposite to the labeled optic tract. In E15-17 embryos, every individual contralaterally projecting ganglion cell outside the ventral-temporal retina was counted. In E18-P3 animals, due to the extremely large numbers of contralaterally projecting ganglion cells present, a sampling method was used to estimate the number of contralaterally projecting ganglion cells outside the ventral-temporal retina. This was done by first counting the number of microsphere-labeled retinal ganglion cells within a single 50$\mu \mathrm{m}$-thick horizontal section through the midsection of the retina. Such a section samples a representative cross section of the embryonic retina and takes into account differential cell densities in central and peripheral retina. An estimate of the total number of ganglion cells in the whole retina was then obtained by dividing the total surface area of the retina by the surface area covered by the $50-\mu \mathrm{m}$-thick horizontal retinal section and then multiplying by the number of ganglion cells counted within the horizontal retinal section.

Results of this analysis are shown in Table 1. The number of ipsilaterally (inappropriately) projecting ganglion cells outside ventral retina from E15 to P3 are listed under column A, while the number of contralaterally (appropriately) projecting ganglion cells outside ventral-temporal retina at the corresponding developmental ages are listed under column B. When the number of inappropriately projecting ganglion cells is expressed as a percentage of all the retinal ganglion cells present outside ventral-temporal retina (right-hand column), it is evident that throughout prenatal development, only a very small fraction of approximately $0.3-0.8 \%$ of the population of retinal ganglion 
cells outside ventral-temporal retina project inappropriately into the ipsilateral optic tract.

\section{Intermixing of ipsilaterally and contralaterally projecting retinal axons}

The results presented thus far all indicate that embryonic retinal ganglion cell axons are specifically routed into the correct pathway following their arrival at the optic chiasm. Two different ways in which this precise pattern of retinal axon routing may be achieved should be considered. The first is a process of axon sorting occurring within the optic nerve segregating ipsilaterally and contralaterally projecting axons into completely different parts of the optic nerve before they enter the chiasm. In this case, ipsilaterally projecting axons might be positioned closest to the entrance of the ipsilateral optic tract and thus enter, while contralaterally projecting axons do not have access to this pathway and therefore project across the midline to the opposite side. Such a process involving rearrangement of retinal axon position within the optic nerve needs to be considered since embryonic retinal axons in the mouse (Silver, 1984; Sretavan, unpublished observations) and other species such as primates (Williams and Rakic, 1985) do not maintain a constant position but instead often wander from one side of the optic nerve to the other as they grow towards the optic chiasm. However, an alternative to the presence of presegregated ipsilateral and contralateral axons which are then passively channeled into the correct optic tract is the possibility that both ipsilaterally and contralaterally projecting retinal axons may be intermixed as they enter the optic chiasm but rely on guidance cues present locally in this region to grow into the correct pathway.

To distinguish between these 2 possibilities, the distribution of ipsilaterally and contralaterally projecting retinal axons as they enter the chiasm was examined at different embryonic ages. In these experiments, DiI was placed into the optic tract of mouse embryos to retrogradely label ipsilaterally projecting retinal axons within the optic nerve on the same side and contralaterally projecting retinal axons in the optic nerve on the oppositc sidc. The distributions of ipsilaterally and contralaterally projecting retinal axons at the entrance to the chiasm were then compared.

Results from these experiments show that ipsilaterally and contralaterally projecting retinal axons are not segregated into different parts of the optic nerve but are instead intermixed as they enter the optic chiasm. An example is presented in Figure 5 , which shows a horizontal section through the optic chiasm region of an E1 7 embryo. As seen here, contralaterally projecting retinal axons are distributed throughout the entire width of the optic nerve as they enter the chiasm. Likewise, although there is a tendency for ipsilaterally projecting axons to be located along the temporal aspect while traveling within the optic nerve, ipsilaterally projecting retinal axons are, in fact, widely scattered in all regions at the entrance of the optic chiasm. A comparison of the distributions of ipsilaterally and contralaterally projecting axons reveals that these 2 axon populations are intermixed so that both ipsilateral and contralateral axons may be found at all locations at the entrance to the optic chiasm. Similar intermixed distributions of ipsilaterally and contralaterally projecting retinal axons were seen at all embryonic ages starting at E15. Thus, embryonic retinal ganglion cell axons are not simply presorted into separate groups of ipsilaterally and contralaterally projecting axons to be passively channeled into the nearest optic tract. However, since a retinal axon close to the entrance of the

\begin{tabular}{|c|c|c|c|}
\hline Age & $\begin{array}{l}\text { Ipsilaterally } \\
\text { projecting } \\
\text { ganglion cells } \\
\text { outside ventral- } \\
\text { temporal retina } \\
\text { A }\end{array}$ & $\begin{array}{l}\text { Contralaterally } \\
\text { projecting } \\
\text { ganglion cells } \\
\text { outside ventral- } \\
\text { temporal retina } \\
\text { B } \\
\end{array}$ & $\begin{array}{l}\text { \% Projection error } \\
(\text { mean } \pm \text { SD) } \\
{[\mathrm{A} /(\mathrm{A}+\mathrm{B})] \times 100}\end{array}$ \\
\hline \multirow{3}{*}{ E15 } & 1 & 80 & \\
\hline & 2 & 149 & $0.86+0.75$ \\
\hline & 0 & 71 & \\
\hline \multirow[t]{3}{*}{ E17 } & 2 & 277 & \\
\hline & 3 & 351 & $0.73 \pm 0.11$ \\
\hline & 2 & 316 & \\
\hline \multirow[t]{3}{*}{ E18 } & 13 & 2624 & \\
\hline & 21 & 3756 & $0.58 \pm 0.10$ \\
\hline & 16 & 2318 & \\
\hline \multirow[t]{2}{*}{ P0 } & 135 & 51,000 & $0.30 \pm 0.05$ \\
\hline & 193 & 58,000 & \\
\hline \multirow[t]{2}{*}{ P3 } & 81 & 45,000 & $0.20 \pm 0.03$ \\
\hline & 107 & 49,000 & \\
\hline
\end{tabular}

Percentage projection error (right-hand column) is calculated as the number of ipsilaterally projecting ganglion cells outside the ventral-temporal third of the retina expressed as a percentage of the total number of ganglion cells in this region.

appropriate optic tract may have an easier task of selecting the correct pathway compared to an axon far away, it is possible that the position of an axon as it enters the chiasm may play some role in axon guidance. Nevertheless, the highly specific routing of intermixed populations of retinal ganglion cell axons into the appropriate optic tracts show that passive channeling of axons cannot be the major mechanism and suggests strongly that developing axons recognize specific pathway cues present in the local environment of the optic chiasm.

\section{Retinal axon trajectories at the optic chiasm}

This suggestion receives additional support when the trajectories of individual ipsilaterally and contralaterally projecting retinal axons within the optic chiasm were traced. To do so, small populations of embryonic retinal axons were first anterogradely labeled by placing fine Dil crystals into localized regions of the retina of fixed embryos. Examples of DiI-labeled retinal axons at the optic chiasm of an E15 embryo after placement of DiI crystals into the ventral-temporal portion of the retina are shown in Figure $6 \mathrm{~A}$. This particular section shows retinal axons which have either just grown into the ipsilateral optic tract or else are growing towards the midline on their way to the other side.

To facilitate the serial reconstruction of the trajectories of individual retinal axons at high magnification, DiI-labeled axons were photoconverted in the presence of $\mathrm{DAB}$ in order to substitute the fluorescent Dil label on axons with a stable DAB reaction product which can be observed with standard brightfield optics (see Materials and Methods). Photoconverted retinal axons from the experiment shown in Figure $6 \mathrm{~A}$ are shown in bright-field at higher magnification in Figure $6 B$. Individual axons can easily be traced and growth cones, including filopodial extensions, are seen in great detail.

The trajectories of embryonic retinal axons were examined in E13-17 embryos, the time during which retinal axons first grow into the chiasm and when adult-like patterns of chiasmatic axon routing are established. Older ages were avoided to min- 
Figure 5. Distributions of ipsilaterally and contralaterally projecting retinal axons as they enter the chiasm at E17. A horizontal view of the chiasm is shown with the optic nerves towards the top. DiI was placed into the optic tract on the right side of the figure labeling ipsilaterally projecting retinal axons in the optic nerve on the same side, and contralaterally projecting axons in the nerve on the opposite side. Note that contralaterally projecting retinal axons are found throughout the entire width of the optic nerve as they enter the optic chiasm (dotted arrows). Similarly, ipsilaterally projecting axons are also distributed at all locations at the entrance of the chiasm (solid arrows). Scale bar, $500 \mu \mathrm{m}$.

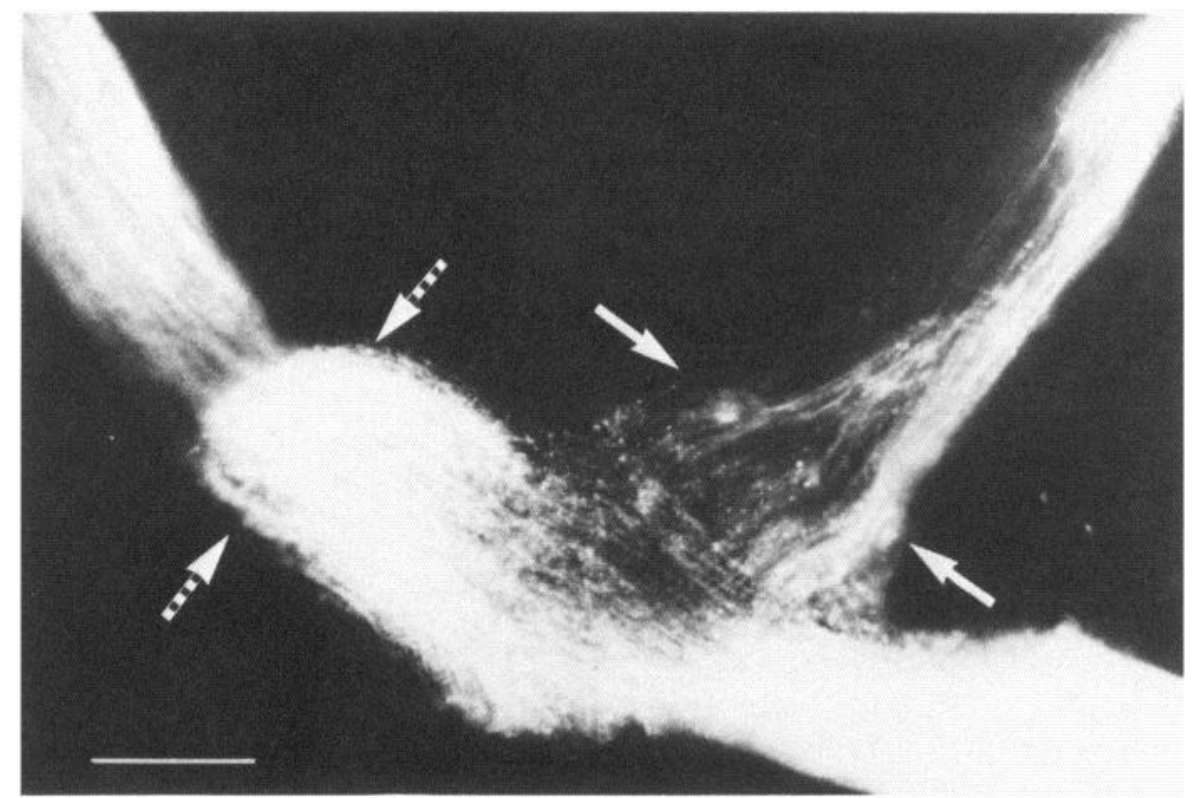

imize the possibility that original axon trajectories may have been distorted by subsequent in-growth of large numbers of retinal axons or by the in-migration and proliferation of glial precursor cells (Small et al., 1987). To reconstruct the course taken by ipsilaterally projecting axons, individual growth cones within the ipsilateral optic tract were first identified, and the main axon was then traced back through the optic chiasm into the optic nerve. To trace contralaterally projecting axons, growth cones at either the midline or in the contralateral optic tract were identified and the axon traced back in order to determine its original course. Axon trajectories reconstructed in this manner very likely closely resemble the original course taken by developing axons and their growth cones through the optic chiasm.

Results of this analysis revealed that both ipsilaterally and contralaterally projecting retinal axons make abrupt turns in trajectory and avoid certain pathways taken by other retinal axons in order to grow into the correct optic tract. Examples are presented in Figure $7 \mathrm{~A}$, showing a group of ipsilaterally and contralaterally projecting axons at the optic chiasm of an E15 embryo. The position of these axons within the optic chiasm are shown in the inset above. Note that axons labeled 1 and 2 enter the chiasm very close to the entrance of the ipsilateral optic tract. However, both axons grow across to bypass this pathway without entering and instead head towards the midline on their way to the opposite side. Within the same section, axons labeled 3 and 4 enter the chiasm some distance away from the entrance of the ipsilateral optic tract. After coursing a certain distance within the optic chiasm, both turn at right angles to head straight into the ipsilateral optic tract. In doing so, these 2 ipsilaterally projecting axons appear to grow directly over other axons heading for the contralateral optic tract (for example, axons 1 and 2 ). Figure $7 B$ shows ipsilaterally and contralaterally projecting axons in an E16 embryo. As shown for E15 axons in Figure $7 A$, contralaterally projecting axons often grow past the entrance of the ipsilateral optic tract, seemingly ignoring this pathway. Ipsilaterally projecting axons, on the other hand, turn and head towards the ipsilateral optic tract, cross- ing over contralaterally projecting axons they encounter along the way.

Figure $7 C$ shows a group of ipsilaterally projecting axons from an E17 embryo. The ipsilaterally projecting axons shown here continue on, ending in growth cones within the ipsilateral optic tract. As seen here, ipsilaterally projecting axons may enter the optic chiasm either close to (for example, axon 1) or quite some distance away from (axon 2) the entrance of the ipsilateral optic tract. Of note, ipsilaterally projecting axons often exhibit an abrupt turn in trajectory of $90^{\circ}$ or more in order to head into the ipsilateral optic tract. Their trajectories before and after the turn are quite straight. Some axons, such as axon 2 , in fact grow almost all the way to the midline before turning back sharply to project into the ipsilateral optic tract.

The prominent sharp turns of ipsilaterally projecting axons raise the question of how axons which have grown well past the entrance of the ipsilateral optic tract may find their way back to the appropriate pathway. It is of note that the trajectories of ipsilaterally projecting axons as they head back towards the ipsilateral optic tract are almost exactly parallel to the course of axons from the opposite eye heading into the same optic tract. Figure $7 D$ shows examples of E17 axons from the opposite eye after they have crossed the midline and are entering the optic tract. Their trajectories past the midline on the way into the optic tract are highly reminiscent of ipsilaterally projecting axons which have turned $90^{\circ}$ to head back towards the ipsilateral optic tract (shown in Fig. $7 \mathrm{C}$ ). Such similarity in trajectories raises the possibility that interactions between developing ipsilaterally projecting axons of one eye and contralaterally projecting axons of the other eye may play a role in axon guidance at the optic chiasm.

A further feature of axon trajectories at the chiasm most often seen at younger embryonic ages is that axons entering the optic chiasm tightly bundled within the same axon fascicle may often make different pathway choices. Figure $7 E$ shows 4 axons in one fascicle growing towards the midline on their way over to the contralateral optic tract, while a fifth axon separates from the others soon after entering the optic chiasm and instead grows 

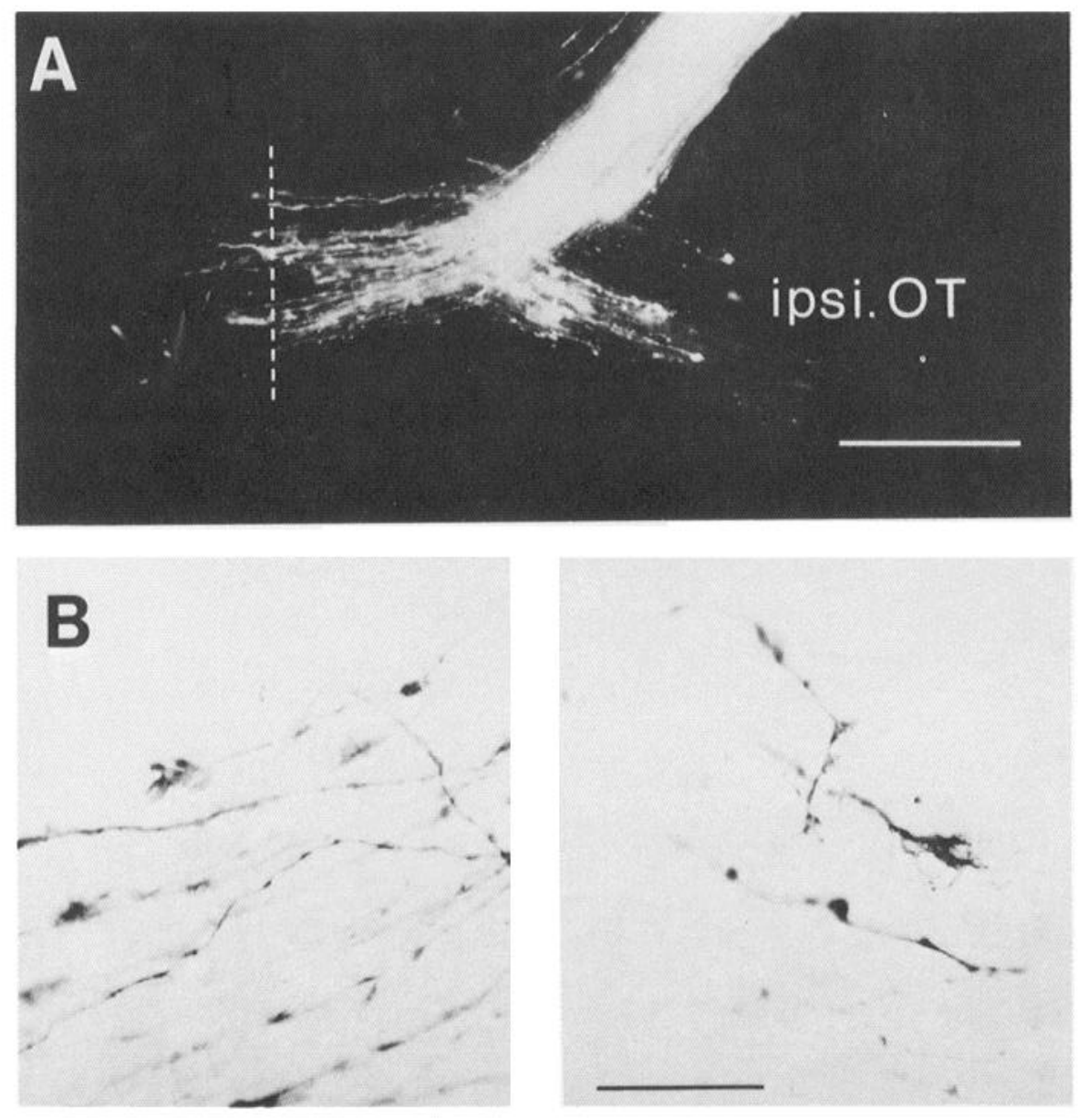

Figure 6. A, Horizontal section through the optic chiasm of an E15 embryo showing retinal ganglion cell axons anterogradely labeled with small crystals of DiI placed in the retina. The dotted line represents the midline. Both ipsilaterally and contralaterally projecting retinal axons are labeled. Scale bar, $100 \mu \mathrm{m}$. $B$, Examples of DAB-labeled retinal axons and growth cones following photoconversion of DiI-labeled material shown in $A$. Retinal axons and growth cones on the right were located within the ipsilateral optic tract, while those on the left were heading across the midline towards the opposite side. (As shown above in Fig. 3, many retinal axons at E1 5 have already grown into the optic tracts for considerable distances; such axons were present in adjacent sections.) into the ipsilateral pathway. Similarly, Figure $7 F$ shows a group of axons from an E14 embryo entering the optic chiasm as part of the same axon fascicle. Two of these axons grow gradually into the ipsilateral optic tract, while 2 others veer away to cross the midline. Thus, during embryonic development, retinal ganglion cell axons entering the optic chiasm at almost identical locations may make divergent pathway choices.

\section{Discussion}

During embryonic development of the mammalian visual system, retinal ganglion cell axons encounter a pathway decision point at the optic chiasm. Results here reveal that beginning early in development, axons of embryonic mouse retinal ganglion cells from different parts of the retina are specifically routed at the optic chiasm into the appropriate optic tracts. This precise axon projection pattern does not result from a presorting of ipsilaterally and contralaterally projecting axons into different parts of the optic nerve, followed by the passive channeling of axons into one or the other optic pathway. Rather, ipsilaterally and contralaterally projecting axons are intermixed as they grow into the chiasm and make abrupt turns in trajectory, crossing over each other as they sort out to enter the correct optic pathway.

\section{Specific routing of axons during development}

Axons in the developing nervous system must often travel over considerable distances to form connections with their target neurons. Along the way, growing axons may be faced with multiple pathway choices and may encounter other sets of developing axons. In insects, the initial formation of axon pathways in the PNS involves the extension of specialized pioneer axons which use guidance cues from strategically placed guidepost cells to navigate through the developing limb and grow towards the CNS (Ho and Goodman, 1982; Bentley and Caudy, 1983). Later axons in turn grow along pioneer axons using them as pathway guides (Klose and Bentley, 1989) to establish the mature pattern of axon pathways. While it is not yet certain to what extent the formation of axon pathways in the nervous system of higher organisms may also involve guidepost cells and the extension of specialized pioneer axons, it is quite clear that developing axons of vertebrate species are remarkably specific in their pathway choice en route to target structures (Dodd and Jessell, 1988, for review). This has been elegantly demonstrated during the formation of peripheral motor nerves in the developing chick (Lance-Jones and Landmesser, 1981; Tosney and Landmesser, $1985 \mathrm{a}, \mathrm{b}$ ) and zebrafish (Eisen et al., 1989) where embryonic motoneurons faced with multiple choices appear to be capable of specifically choosing the correct pathway and grow towards the appropriate target muscles. Few errors appear to be made as the mature pattern of motor nerves is formed by directed axon outgrowth early in development.

Here, the ability of developing retinal ganglion cells to make appropriate pathway decisions as they grow towards central targets was examined in the mouse embryo. In these studies, 
A

E 15

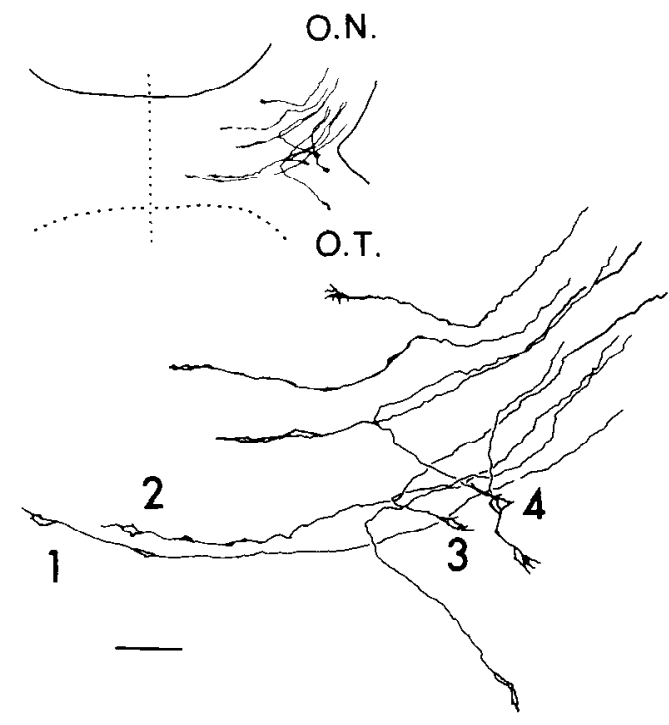

C

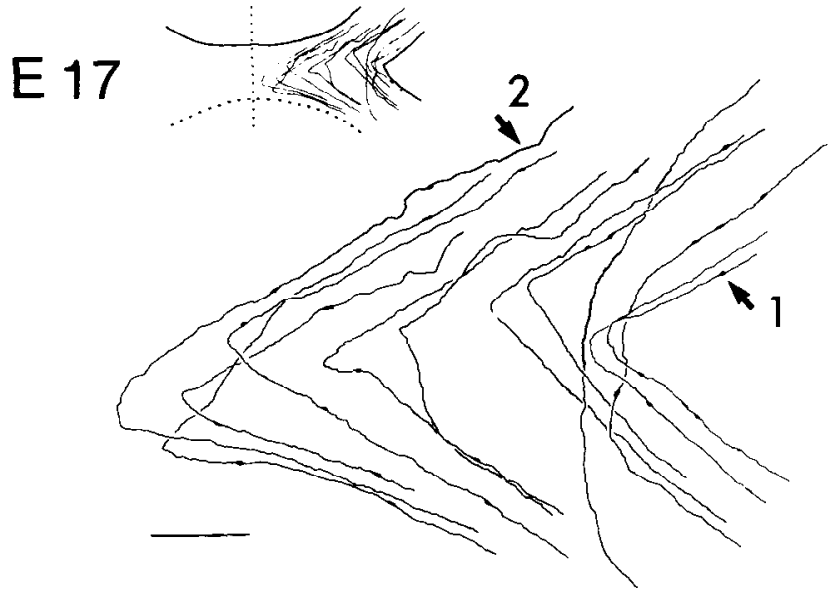

$E$

E 13
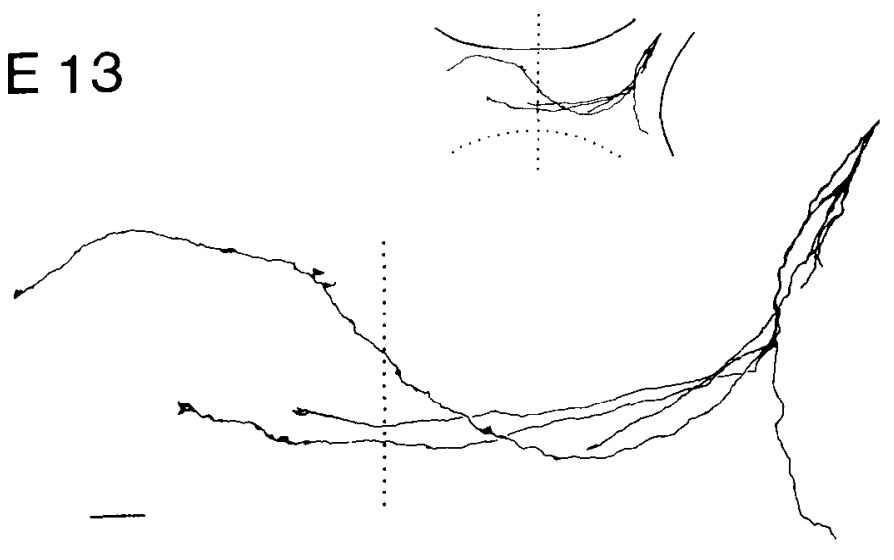

B

E 16
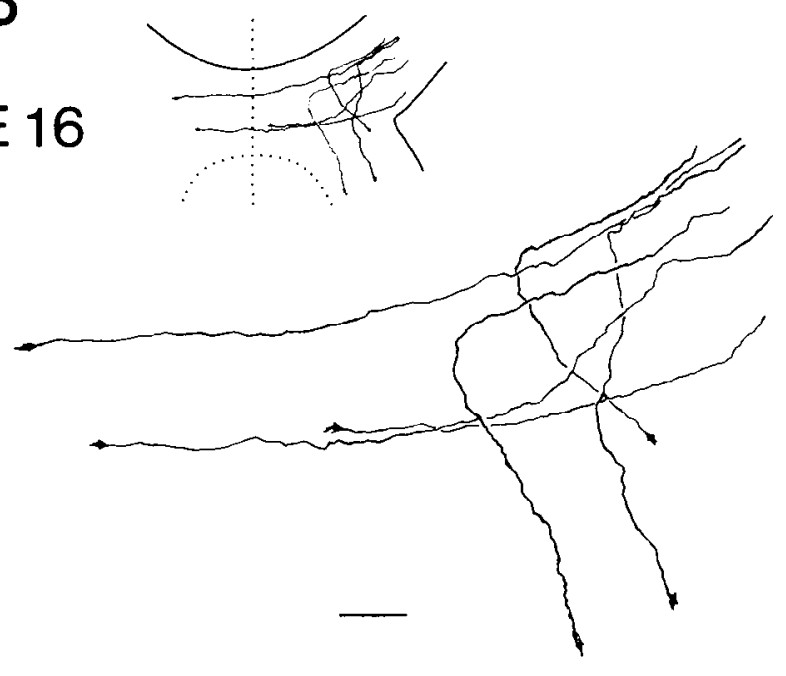

D

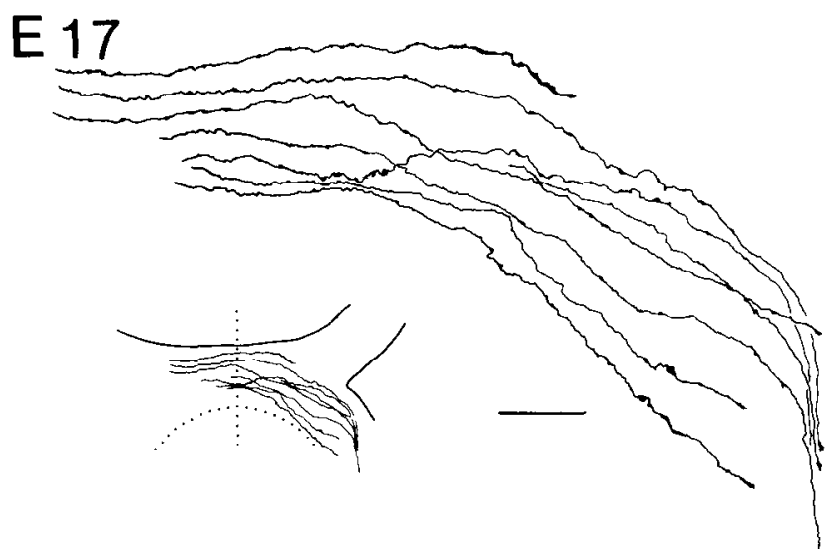

$F$

E 14

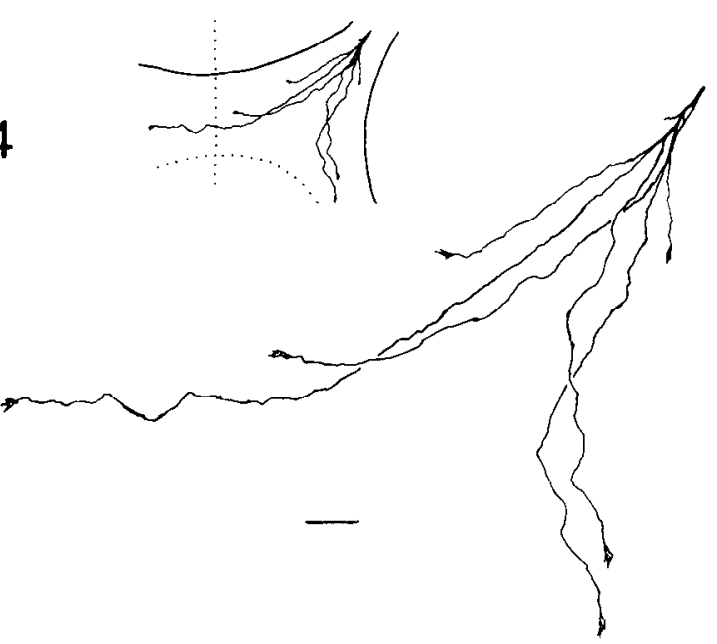

Figure 7. Trajectories of embryonic retinal ganglion cell axons within the optic chiasm region at different embryonic ages. In each case, the position of the axons within the optic chiasm is shown in an inset. $A$ and $B$, Axons from an E15 and an E16 embryo. Axons labeled 1 and 2 in $A$ originally enter the chiasm close to the entrance of the ipsilateral optic tract but bypass this pathway without entering. Axons labeled 3 and 4 grow into the chiasm some distance away from the entrance of the ipsilateral optic tract but, after coursing for a short distance, turn abruptly to head into the 
the specificity of embryonic retinal ganglion cell axon projections was determined as retinal axons encounter a major pathway branch point at the optic chiasm. The results show that adult-like patterns of retinal ganglion cell axon routing can be found soon after axons arrive at the chiasm, strongly suggesting that embryonic retinal ganglion cells, when faced with a pathway choice, are indeed capable of selectively choosing the correct optic tract. Unlike invertebrates, which may have only relatively few axons within a given pathway, the rodent visual system consists of tens of thousands of retinal axons growing into the chiasm region over an extended period in development. Despite this difference in the number of axons, the adult pattern of visual projections at the mouse optic chiasm, like the pattern of precise axon pathways in invertebrates and lower vertebrates, results from highly specific axon outgrowth early in development. Such specificity in retinal axon projections is also found during regeneration in the amphibian visual system. Retinal axons reentering the optic tectum do so via either 1 of 2 arms of the optic tract in a manner appropriate for their retinal site of origin (Bernhardt, 1989).

While embryonic retinal ganglion cells appear to be capable of specifically choosing the correct pathway, a small number of retinal ganglion cells do make mistakes and project into the wrong optic tract. In this regard, retinal projections at the chiasm appear to be somewhat different from motoneuron axon projections in the chick where reportedly none or exceedingly few axons grow into inappropriate pathways (Tosney and Landmesser, 1985a). Although it is possible that retinal ganglion cell axons in mammals and motoneuron axons in the chick may differ in their pathfinding ability, it seems more likely that developing axon populations in both species exhibit a small amount of projection error that is inherent to the process of axon pathfinding. Since, as results here have shown, this projection error is likely to be very small, only few misroutings would be expected during the formation of pathways consisting of relatively small numbers of axons. However, given the large numbers of retinal axons growing through the optic chiasm, even a small degree of error in the pathway decision process will result in significant numbers of inappropriately routed axons.

\section{Specific axon outgrowth and elimination of routing errors}

By examining the development of a major CNS axon pathway beginning at early stages of its formation, this study provides a better understanding of the relative contributions of specific axon outgrowth versus elimination of routing errors in the cstablishment of mature patterns of axon pathways in the mammalian CNS. Previous studies examining the postnatal development of the visual system in several mammalian species have noted the presence of incorrectly projecting retinal ganglion cells (Jeffrey and Perry, 1982; Martin et al., 1983; Insausti et al., 1984; Jacobs et al., 1984). Using long-term neuronal tracers, it was shown that inappropriately projecting ganglion cells, such as ipsilaterally projecting ganglion cells outside ventral-temporal retina in the rodent, are gradually eliminated during postnatal life. Furthermore, the magnitude of the loss of inappropriately projecting ganglion cells (Jeffrey and Perry, 1982; Martin et al., 1983; Insausti et al., 1984; Jacobs et al., 1984) appears to be far greater than that of general retinal ganglion cell death occurring in the retina postnatally (Lam et al., 1982; $\mathrm{Ng}$ and Stone, 1982; Perry et al., 1983; Williams et al., 1983; Crespo et al., 1985). This suggests that such projection errors may in fact be selectively eliminated from the nervous system. Indeed, very few inappropriately projecting ganglion cells are detected in the adult animal (Stone and Fukuda, 1974; Drager and Olsen, 1980; Lund et al., 1980; Jacobs et al., 1984).

From these postnatal studies demonstrating the presence of projection errors at the chiasm after birth, it was not clear whether axon routing may be even more imprecise at earlier stages and that the elimination of routing errors represented the major mechanism by which the adult pattern of axon routing is formed at the optic chiasm. However, results from the present study examining retinal axon outgrowth starting at early stages of development, together with results from these previous studies, provide a more complete picture of the development of this pathway. Thus, in the visual system, 2 different developmental processes together help form the adult pattern of retinal axon routing at the optic chiasm. The primary strategy employed by retinal ganglion cells appears to be one of specific axon outgrowth beginning at embryonic stages of development. The number of chiasmatic routing errors associated with this remarkably precise outgrowth is very small relative to the large number of axons growing through the optic chiasm. As shown in previous studies described above, inappropriate projections that do occur are later gradually eliminated through a second process of selective cell death during postnatal development to give rise to the mature pattern present in the adult animal.

The formation of mature patterns of axon pathways in other regions of the mammalian CNS also involves the elimination of transient axon projections routed to inappropriate target regions (Innocenti, 1981; O'Leary et al., 1981; Ivy and Killackey, 1982; Stanfield et al., 1982; Feng and Brugge, 1983; reviewed in Cowan et al., 1984). The available evidence suggests that in these systems, large numbers of cortical neurons not only send axon projections along appropriate pathways but also frequently send transient axon projections into pathways from which the axon is later withdrawn. However, since the specificity of cortical axon routing into appropriate versus inappropriate pathways has not been quantitatively examined from the earliest stages, the importance of specific axon outgrowth compared to pathway error elimination to the formation cortical axon pathways is not known. It is possible that unlike retinal projections at the optic chiasm, mature patterns of axon pathways elsewhere

\footnotetext{
ipsilateral optic tract. O.N., optic nerve; $O . T$., optic tract. Scale bar, $50 \mu \mathrm{m}$. B, Similar to E15 axons shown in $A$, retina axons at E16 also exhibit abrupt turns in trajectory crossing over each other to enter the optic tracts. Scale bar, $50 \mu \mathrm{m}$. $C$, Ipsilaterally projecting axons from an E17 embryo. Their growth cones within the ipsilateral optic tract are not shown. Ipsilaterally projecting axons may enter the chiasm either close to (axon l) or some distance away (axon 2) from the ipsilateral optic tract. Axons shown here, including those which grow almost to the midline, turn abruptly to head back and enter the ipsilateral optic tract. Scalc bar, $200 \mu \mathrm{m} . D$, Contralaterally projecting axons from an E17 embryo. Only the portion of their trajectories past the midline as they grow into the optic tract is shown. Note that the angle and straight course of their trajectories closely parallel those of ipsilaterally projecting axons turning back and heading into the ipsilateral optic tract (shown in $C$ ). Scale bar, $200 \mu \mathrm{m}$. $E$ and $F$, Axons entering the chiasm bundled together within the same fascicle at E13 and E14. Note that axons entering the chiasm in nearly identical positions may separate and grow independently into either the ipsilateral or contralateral optic tract. Scale bar, $25 \mu \mathrm{m}$.
} 
in the CNS are not built upon an adult-like pattern that is established early in development. Instead, the mature pattern of axon routing may be refined from an initially more widespread distribution involving transient projections to inappropriate regions. This appears to be the case during rodent cortical development, where initially all corticofugal neurons projecting to subcortical targets seem to elaborate a common pattern of axon collaterals. The distinct patterns of axon collaterals appropriate for mature corticofugal neurons in specific cortical areas are formed only after certain axon collaterals are selectively eliminated (Stanfield and O'Leary, 1985; O'Leary and Terashima, 1988). In this context, transient axon projections which are elaborated by nearly all members of a given neuronal population need not represent errors or a breakdown in the pathfinding process. Rather, such transient axon projections may be formed correctly in direct response to specific pathway cues which are transiently expressed simultaneously in many rcgions of the CNS during development.

\section{Axon guidance cues at the optic chiasm}

Although the cellular basis of specific retinal ganglion cell axon routing at the chiasm remains unclear, the molecular mechanisms underlying retinal axon targeting within visual structures are beginning to be understood. Studies of axonal innervation in the chick optic tectum (Walter et al., 1987a, b) and more recently in the mouse superior colliculus (Godement and Bonhoeffer, 1989), demonstrate that retinal axons in vitro recognize specific molecular cues associated with the membrane surface of tectal cells. This recognition mechanism is thought to direct the formation of connections between axons from different parts of the retina and tectal neurons in precise target regions. At the optic chiasm, reconstructions of individual embryonic retinal axons show that ipsilaterally and contralaterally projecting retinal axons, initially intermixed at the chiasm, make abrupt corrections in their direction of growth to selectively enter the appropriate optic tract. These results strongly suggest that a specific recognition process is also operating at the optic chiasm and that local axon guidance cues present in this region enable retinal axons to seek out the correct pathway.

Axon guidance cues may arise as a result of interactions between retinal axons and neuroepithelial cells at the optic chiasm. During development, retinal axons entering the optic chiasm acquire complex growth cone morphologies (Bovolenta and Mason, 1987) and grow in close physical contact with neuroepithelial cells (Silver, 1984). Ipsilaterally and contralaterally projecting axons course in between the end feet of neuroepithelial cells as they sort out from each other to enter the appropriate optic tracts. In addition, it is known that both NCAM (Silver and Ruthishauser, 1984) and laminin (Liesi and Risteli, 1989) are found in the regions of neuroepithelial cell end feet, providing a molecular basis for the close interaction between developing retinal axons and neuroepithelial cells. However, it is not known whether neuroepithelial cells simply provide a favorable substrate for axonal growth or whether subsets of neuroepithelial cells may also express specific guidance cues directing retinal axons into the appropriate ipsilateral and contralateral optic pathways. It should be noted that such guidance cues need not be fixed to the membrane surface of neuroepithelial cells. It is possible that developing retinal axons respond at a distance to guidance cues secreted from the optic chiasm in a fashion similar to axon guidance in several periph- eral and CNS systems (Lumsden and Davies, 1986; TessierLavigne et al., 1988; Heffner et al., 1990).

Another set of interactions to be considered are those occurring between axons from the 2 eyes. For instance, ipsilaterally projecting axons may be guided into the ipsilateral optic tract by axons from the opposite eye projecting into the same pathway. However, evidence shows that ipsilaterally projecting axons do not rely solely on axons from the opposite eye in order to enter the ipsilateral optic tract. Following the removal of one eye in cat embryos before retinal axons have arrived at the chiasm, axons from the remaining eye are still routed into the ipsilateral and contralateral optic tracts (Sretavan and Shatz, 1986). Furthermore, a subsequent study in the mouse showed that these ipsilaterally projecting axons originated from the correct ventral-temporal part of the retina (Godement et al., 1987b).

A clue to how axons from ventral-temporal retina may be directed into the ipsilateral optic tract during early development is provided by the observation that the very first retinal ganglion cells to be born in the dorsal region of the retina (Drager, 1985) do not only establish a contralateral pathway at the chiasm but also reportedly form an ipsilateral projection (Godement et al., 1987a). This finding is notable since results from the present study show that a day or two later at E15, the ipsilateral projection originates almost exclusively from ventral-temporal retina and not from dorsal retina. Although it is possible that ipsilaterally projecting ganglion cells may migrate from their original position in dorsal retina to ventral-temporal retina, it is more likely that the earliest born ganglion cells either die or form only a transient ipsilateral projection that is lost soon after the formation of the ipsilateral projection from ventral-temporal retina. One function of this early transient ipsilateral axon projection may be to guide later-arriving ventral-temporal axons into the ipsilateral optic tract. Such a function is similar to the role proposed for axons of transient subplate neurons in guiding the formation of corticofugal projections from the embryonic neocortex (McConell et al., 1989). If this early transient ipsilateral projection does indeed function in this manner, then prevention of its formation should greatly affect the number of retinal axons routed into the ipsilateral pathway.

\section{References}

Bentley D, Caudy M (1983) Pionccr axons losc directed growth after selective killing of guidepost cells. Nature 304:62-65.

Bernhardt R (1989) Axonal pathfinding during the regeneration of the goldfish optic pathway. J Comp Neurol 284:119-134.

Bovolenta P, Mason C (1987) Growth cone morphology varies with position in the developing mouse visual pathway from retina to first targets. J Neurosci 7:1447-1460.

Cowan WM, Fawcett JW, O'Leary DDM, Stanfield BB (1984) Regressive events in neurogenesis. Science 225:1258-1265.

Crespo D, O'Leary DDM, Cowan WM (1985) Changes in the numbers of optic nerve fibers during late prenatal and postnatal development in the albino rat. Dev Brain Res 19:129-134.

Dodd J, Jessell T (1988) Axon guidance and the patterning of neuronal projections in vertebrates. Science 242:692-699.

Drager UC (1985) Birth dates of retinal ganglion cells giving risc to the crossed and uncrossed optic projections in the mouse. Proc R Soc London [Biol] 224:57-77.

Drager UC, Olsen JF (1980) Origin of crossed and uncrossed retinal projections in pigmented and albino mice. J Comp Neurol 191:383412.

Eisen J, Myers PZ, Westerfield M (1986) Pathway selection by growth cones of identified motoneurones in live zebra fish embryos. Nature 320:269-271.

Eisen J, Pike S, Debu B (1989) The growth cones of identified mo- 
toneurons in embryonic zebrafish select appropriate pathways in the absence of specific cellular interactions. Neuron 2:1097-1 104 .

Feng JZ, Brugge JF (1983) Postnatal development of auditory callosal connections in the kitten. J Comp Neurol 214:416-426.

Godement P, Bonhoeffer F (1989) Cross-species recognition of tectal cues by retinal fibers in vitro. Development 106:313-320.

Godement $P$, Vanselow J, Thanos S, Bonhoeffer F (1987a) A study in developing visual systems with a new method of staining neurones and their processes in fixed tissue. Development 101:697-713.

Godement P, Salaun J, Metin C (1987b) Fate of uncrossed retinal projections following early or late prenatal monocular enucleation in the mouse. J Comp Neurol 255:97-109.

Goodman C, Bastiani M, Doe C, du Lac S, Helfand K, Kuwada J, Thomas JB (1984) Cell recognition during neuronal development. Science 225:1271-1279.

Guillery RW (1983) The optic chiasm of the vertebrate brain. Contr Sensory Physiol 7:39-73.

Heffner CD, Lumsden AGS, O'Leary DDM (1990) Target control of collateral extension and directional axon growth in the mammalian brain. Science 247:217-220.

Ho RK, Goodman C (1982) Peripheral pathways are pioneered by an array of central and peripheral neurons in grasshopper embryos. Nature 297:404-406.

Honig M, Hume RI (1986) Fluorescent carbocyanine dyes allow living neurons of identified origin to be studied in long term cultures. J Cell Biol 103:171-187.

Innocenti GM (1981) Growth and reshaping of axons in the establishment of visual callosal connections. Science 212:824-827.

Insausti R, Blakemore C, Cowan WM (1984) Ganglion cell death during development of ipsilateral retino-collicular projection in golden hamster. Nature 308:362-365.

Ivy GO, Killackey HP (1982) Ontogenetic changes in the projections of neocortical neurons. J Neurosci 2:735-743.

Jacobs DS, Perry VH, Hawken MJ (1984) The postnatal reduction of the uncrossed projection from the nasal retina in the cat. I Neurosci $4: 2425-2433$.

Jeffery G, Perry VH (1982) Evidence for ganglion cell death during development of the ipsilateral retinal projection in the rat. Dev Brain Res 2:176-180.

Katz LC, Burkhalter A, Dreyer WJ (1984) Fluorescent latex microspheres as a retrograde marker for in vivo and in vitro studies of visual cortex. Nature 310:498-500.

Klose M, Bentley D (1989) Transient pioneer neurons are essential for formation of an embryonic peripheral nerve. Science 245:982984.

Lam KA, Sefton AJ, Bennett MR (1982) Loss of axons from the optic nerve of the rat during early postnatal development. Dev Brain Res $3: 487-491$.

I ance-Jones C, Landmesser L (1981) Pathway selection by embryonic chick motoneurones in an experimentally altered environment. Proc R Soc London [Biol] 214:19-52.

Landmesser L (1984) The development of specific motor pathways in the chick embryo. Trends Neurosci 7:336-339.

Liesi P, Risteli L (1989) Glial cells of mammalian brain produce a variant form of laminin. Exp Neurol 105:86-92.

Lumsden A, Davies A (1986) Chemotropic effect of specific target epithelium in the developing mammalian nervous system. Nature 323:538-539.

Lund RD, Land PW, Boles J (1980) Normal and abnormal uncrossed retinotectal pathways in rats: an HRP study in adults. J Comp Neurol 189:711-720.

Maranto A (1982) Neuronal mapping: a photooxidation reaction makes Lucifer Yellow useful for electron microscopy. Science 217:953-955.

Martin PR, Sefton AJ, Dreher B (1983) The retinal location and fate of ganglion cells which project to the ipsilateral superior colliculus in nconatal albino and hooded rats. Neurosci Lett 41:219-226.
McConell SK, Ghosh A, Shatz CJ (1989) Subplate neurons pioneer the first axon pathway from the cerebral cortex. Science 245:978982.

Morest DK (1970) The pattern of neurogenesis in the retina of the rat. Z Anat Entwick Gesch 131:45-67.

$\mathrm{Ng}$ AYK, Stone J (1982) The optic nerve of the cat: appearance and loss of axons during normal development. Dev Brain Res 5:263271.

O'Leary DDM, Terashima T (1988) Cortical axons branch to multiple subcortical targets by interstitial axon budding: implications for target recognition and "waiting periods." Neuron 1:901-910.

O'Leary DDM, Stanfield BB, Cowan WM (1981) Evidence that the early postnatal restriction of the cells of origin of the callosal projection is due to the elimination of axonal collaterals rather than to the death of neurons. Dev Brain Res 1:607-617.

Perry VH, Henderson Z, Linden R (1983) Postnatal changes in retinal ganglion cell and optic axon populations in the pigmented rat. J Comp Neurol 219:356-368.

Sandell JH, Masland RH (1988) Photoconversion of some fluorescent markers to a diaminobenzidine product. J Histochem Cytochem 36: 555-559.

Silver J (1984) Studies on the factors that govern directionality of axonal growth in the embryonic optic nerve and at the chiasm of mice. J Comp Neurol 223:238-251.

Silver J, Rutishauser U (1984) Guidance of optic axons in vivo by a preformed adhesive pathway on neuroepithelial end-feet. Dev Biol 106:485-499.

Small RK, Riddle P, Noble M (1987) Evidence for migration of oligodendrocyte type- 2 astrocyte progenitor cells into the developing rat optic nerve. Nature 328:155-157.

Sretavan DW (1989) Axon pathfinding in the embryonic mouse visual system. Soc Neurosci Abstr 15:960.

Sretavan DW, Shatz CJ (1986) Prenatal development of cat retinogeniculate axon arbors in the absence of binocular interactions. $J$ Neurosci 6:990-1003.

Stanfield BB, O'Leary DDM (1985) The transient corticospinal projection from the occipital cortex during the postnatal development of the rat. J Comp Neurol 238:236-248.

Stanfield BB, O'Leary DDM, Fricks C (1982) Selective collateral elimination in early postnatal development restricts cortical distribution of rat pyramidal tract ncuroncs. Naturc 298:371-373.

Stone J, Fukuda $Y$ (1974) The naso-temporal division of the cat's retina reexamined in terms of $\mathrm{Y}-\mathrm{X}, \mathrm{X}$ - and W-cells. J Comp Neurol 155:377-394.

Tessier-Lavigne M, Plazcek M, Dood J, Jessell T (1988) Chemotropic guidance of developing axons in the mammalian central nervous system. Nature 336:775-778.

Tosney K, Landmesser L (1985a) Specificity of early motoneuron growth cone outgrowth in the chick embryo. J Neurosci 5:2336-2344.

Tosney K, Landmesser L (1985b) Growth cone morphology and trajectory in the lumbosacral region of the chick embryo. J Neurosci 5: 2345-2358.

Walter J, Kern-Veits B, Huf J, Stolze B, Bonhoeffer F (1987a) Recognition of position-specific properties of tectal cell membranes by retinal axons in vitro. Development 101:685-696.

Walter J, Henke-Fahle S, Bonhoeffer F (1987b) Avoidance of posterior tectal membranes by temporal retinal axons. Development 101:909913.

Westerfield M, Eisen J (1988) Neuromuscular specificity: pathfinding by identified motor growth cones in a vertebrate embryo. Trends Neurosci 11:18-22.

Williams RW, Rakic P (1985) Dispersion of growing axons within the optic nerve of the embryonic monkey. Proc Natl Acad Sci USA 82: 3906-3910. 